\title{
EDITORIALS
}

\section{Communicative Competence: A Framework for Understanding Language Barriers in Health Care}

\author{
Jessica Gregg, $M D, P h D^{7}$ and Somnath Saha, $M D, M P H^{2}$ \\ 'Division of General Internal Medicine \& Geriatrics, Oregon Health \& Science University, Portland, OR, USA; ${ }^{2}$ Section of General Internal \\ Medicine, Portland VA Medical Center, Division of General Internal Medicine \& Geriatrics, Oregon Health \& Science University, \\ Portland, OR, USA.
}

J Gen Intern Med 22(Suppl 2):368-70

DOI: $10.1007 / \mathrm{s} 11606-007-0364-4$

(c) Society of General Internal Medicine 2007

$\mathrm{W}$ hen clinicians and their patients speak different languages, patient care and clinical outcomes suffer. Specifically, when patients have limited English proficiency (LEP) they have worse access to care, receive poorer quality care, are less likely to understand and adhere to care plans, and are less satisfied with their physicians and the care they do receive. ${ }^{1}$

These data are not surprising: if a clinician and a patient cannot understand one another's words, there is little likelihood that the patient will be able to effectively communicate his or her complaints or that the clinician will be able to effectively communicate a diagnosis and recommendations. Yet, while it might seem obvious that language barriers impede care and interfere with optimal clinical outcomes, significant questions remain regarding how and why language differences affect care. ${ }^{1}$ For instance, in this issue of the Journal of General Internal Medicine (JGIM), Cheng et al. demonstrate that even when Hispanic patients are comfortable communicating in English during a clinical encounter, they are significantly less likely to receive recommended health services if they speak Spanish at home, when compared to Hispanic patients who speak English at home. In this issue of the Journal of General Internal Medicine (JGIM), Cheng et al. demonstrate that even when Latino patients are comfortable communicating in English, they are significantly less likely to receive recommended health services if they speak Spanish at home, when compared to Latino patients who speak English at home. ${ }^{2}$ How do language differences outside the clinical encounter affect care within it?

Also, what does the language concordant physician add to the clinical encounter that a translation service does not? Research has repeatedly shown that when LEP patients have a language-concordant physician, their clinical outcomes and satisfaction with care are significantly better than outcomes for similar patients working with an interpreter. ${ }^{3-6}$ Several papers in this JGIM supplement corroborate this finding. ${ }^{7-9}$ Why is the translation of a language during a clinical encounter a necessary but not sufficient condition for overcoming languagebased barriers to care?

One potentially helpful starting point for approaching these and other similar questions is to consider that not all research- ers studying language and language barriers in medicine are necessarily studying the same entity. Some are examining language as a shared structure or system, what the Swiss linguist Saussure famously termed langue, and what we commonly think of as language (English, Spanish, or Russian, for example). ${ }^{10}$ This dimension of language includes the database of words used by a group of people and the formal rules that guide the use of those words. Other researchers are examining the use of language by individuals, what we commonly think of as speech and what Saussure termed parole. This latter dimension encompasses not only the "database" but the gestures, the delivery, and the context - social, cultural, historical, etc. - that give the words and phrases from the database their full meaning in a given setting or situation. Understanding, even in a cursory way, how these two linguistic dimensions differ, and understanding which aspect a researcher is addressing, may allow us to better perceive what is actually being examined in research on language barriers, what is potentially being missed, and how to evaluate conclusions and solutions.

When language is considered to be simply a shared system of grammar and words (i.e., when considering langue), language barriers can be considered primarily a problem of translation or "code-switching," in which individuals who speak different languages require a code-breaker (generally an interpreter) who can allow each party to decipher what the other is saying. ${ }^{11}$ Clearly, the ability to provide this type of deciphering, or translation, is critical to ensuring effective communication. When patients have access to interpreter services (particularly when the interpreters are professionally trained), patient comprehension increases, health care utilization equalizes, and both LEP patients and their clinicians are more likely to be satisfied with the clinical encounter. ${ }^{1,12,13}$

Research and policy that attempt to solve problems of translation generally have the goal of improving the accuracy and efficiency of methods for translating words from one language into words with equivalent or near-equivalent counterparts in another language. Therefore, this work tends to focus on the logistics of interpreter services: expense, training, availability, optimal interpretive modality, and the willingness and ability of providers to offer services. Several articles in this supplement add to this body research, examining, among other issues, interpreter training, ${ }^{14}$ medical student training in the use of interpreters, ${ }^{15}$ barriers and potential barriers to adopting interpretive services among private practice physicians, ${ }^{16}$ and optimal strategies for providing interpretive services. ${ }^{8,9,17}$ 
When considered as speech (i.e., parole), however, language must be considered a much more dynamic medium, constantly changing depending on who is using it and what he or she is using it for. The field of sociolinguistics is based on the idea that speakers are, first and foremost, social actors and that language is a symbolic resource used by speakers to make sense of the world and their place within it. For instance, speakers use language to demonstrate status or power (e.g., through the use of honorifics or the use of medical jargon by a physician), to demonstrate belonging (e.g., through the use of slang by teenagers to exclude parents or the choice to use or discard a regional accent), to create art, or as part of ritual (e.g., prayers in church or synagogue). Furthermore, not all actors will necessarily agree upon what types of speech are "correct" in certain contexts and at certain times. Language, then, is also negotiated and contested. ${ }^{18}$

Thus, linguistic differences are not just differences in words but also differences in the concepts behind words and in the contexts that shape the meanings of words. ${ }^{18,19}$ Understanding the role language differences play in medical encounters and their impact on clinical outcomes must necessarily include an understanding of the larger context in which language takes place. Sociolinguists refer to this understanding as "communicative competence. ${ }^{20}$ " As explained by linguist John Gumperz, "Whereas linguistic competence covers the speaker's ability to produce grammatically correct sentences, communicative competence describes his ability to select, from the totality of grammatically correct expressions available to him, forms which appropriately reflect the social norms governing behavior in specific encounters. ${ }^{21}$ "

Medical anthropologist Richard Parker provided an example of the dangers of lack of communicative competence in his work in Brazil during the early years of the AIDS epidemic. Parker found that early AIDS prevention literature imported from the United States focused primarily on promoting safe sex among gay men. However, in Brazil, where the sexual culture is "characterized by its flexibility and its fluidity" (p. 163), the relationship between sexual behavior and sexual identity is less direct than it is in the United States. Parker describes two parallel systems: the medical/scientific system, in which terms like "homosexual" and "heterosexual" are understood in much the same way that they are in the United States, and a "folk" system, in which men who have sex with men do not always identify as homosexual, particularly if they are considered the "active" partner in the relationship, and in which transgression, the breaking of official rules of behavior, is often one of the goals of sexual activity. Thus, imported AIDS prevention literature that urged "safe sex" among gays and homosexuals was rendered ineffectual in a context in which the term safe sex seemed an oxymoron and in which many at-risk individuals did not identify as gay. ${ }^{22}$

Dohan and Levintova's article in this issue of JGIM provides another example of the critical need for communicative competence in clinical scenarios. ${ }^{23}$ The authors demonstrate that the word "cancer" holds different meanings for Russian émigrés in California than it does for their medical providers. For providers, the word represents a disease entity to be treated. For many émigrés in the study, the word "cancer" was almost unspeakable, representing a death sentence and loss of hope. As an informant in their study notes, the émigrés are "coming from a culture where the treatments that are available here simply did not exist. There's no treatment, there's no cure, there's no hope. ${ }^{23 "}$ Dohan and Levintova suggest that these alternate understandings of the word contributed to tension and mistrust between providers and some of their émigré patients. Thus, whereas the word "cancer" might be amenable to direct translation (cancer in English, pak in Russian), the meaning behind that word, the context in which that meaning developed, and the use of the word may vary dramatically between languages and cultures and may significantly impact the success or failure of the clinical encounter. (We should also note that the cultural norm of nondisclosure of cancer diagnoses has been found in other cultures as well, including, in the past, in the United States.) ${ }^{24-26}$

To decrease the possibility that a clinical encounter will be derailed by communicative incompetence, research and policy must consider not only the role of translation in clinical services but also the role of interpretation, in the full sense of the word. That is, it must consider interpretation as a process of communicating ideas and the context in which those ideas take shape. ${ }^{11,27}$ In studies of medical interpretation among the Inuit in Canada, O'Neil and colleagues found that most problems in communication between the Inuit and healthcare providers arose not when interpreters were unable to adequately translate words but, rather, when they were unable or unwilling to interpret the cultural and social milieus from which those words and their meanings arose. ${ }^{28,29}$

O'Neil and colleagues have argued convincingly, based on their findings, that interpreters are often much more valuable to the clinical encounter when they serve not just as "linguistic conduits" but as cultural brokers as well. ${ }^{29}$ Interpreters and émigrés interviewed in the study by Dohan and Levintova echo that suggestion, noting that "interpreters could help address cultural differences in disclosure and social differences in treatment expectation if they were trusted to move away from 'word by word' translation and to broker relationships between care providers and patients. ${ }^{23}$ " The notion of interpreters as cultural brokers is an attractive one, a potential remedy for the problems arising from attending exclusively to langue in interpreted encounters, without sufficient attention to parole. Yet this solution, like any, will require development and study. Some readily apparent drawbacks include the possibility that cultural brokers might make assumptions about a patient's cultural affiliations and preferences, based on ethnicity, age, or other characteristics; might substitute his or her own interpretation of cultural norms when they are not shared by the patient; or might use "cultural appropriateness" as a blanket excuse for not transmitting information that is uncomfortable, rather than inappropriate, to divulge. In our experience, these problems already exist in many interpreted encounters. Making the issue of cultural brokering explicit should help bring them to the surface so that providers, patients, interpreters, and researchers can face them head-on.

Other avenues to more holistic interpretation also warrant consideration and study. Interpreters should not be the only ones attending to the cultural and contextual aspects of language and communication. As has been loudly advocated in recent years, providers must be also trained to recognize the importance of cultural dimensions of communication among both LEP and English-speaking patients. We do not believe that it is appropriate, or even possible, for a provider to be versed in the complex cultural and contextual milieus that influence the parole of every patient in every situation. However, he or she can be cognizant of the role of culture in 
communicating with patients, and develop the skills to elicit information about context and culture, one patient at a time. ${ }^{30}$

Finally, it is worth noting again that studies have found care to be better in language-concordant encounters. ${ }^{3-9}$ This benefit may stem simply from a more accurate and complete transmission of words in an "unfiltered" exchange. We suspect, though, that it may also reflect the ability of bilingual/bicultural providers to attend to both langue and parole-both words and the context that gives them their full meaning. Studies demonstrating better communication between racially and ethnically concordant patients and providers support this assertion. ${ }^{31}$ An important part of the effort, then, to reduce language barriers between patients and providers is to increase the linguistic and cultural diversity of the healthcare workforce and to give patients greater choice in selecting providers whom they can understand and who can understand them.

Ultimately, if we are to effectively care for the millions of Americans who do not consider English their first language, we need to attend to both their langue and their parole. We need to provide clear, proficient language translation so that patients and clinicians can understand each other's words. However, we also need to ensure that physicians have the opportunity to understand not just what a patient says but also what that patient means when he or she speaks. This may be the more difficult task. We might start by simply recognizing that the two tasks, translating langue and interpreting parole, are in fact quite different and that research or policy addressing one does not automatically take the other into account. From that starting point, it may be more possible to recognize not only what we know but also what we may be overlooking and how to go about filling the gaps in our knowledge and practice.

Acknowledgments: The authors would like to thank Debra Spitulnik, PhD, for her helpful suggestions. Dr. Saha is supported by an Advanced Research Career Development award from the Department of Veterans Affairs, Health Services Research \& Development Service, and by a Generalist Physician Faculty Scholars award from the Robert Wood Johnson Foundation. The opinions expressed in this editorial are those of the authors and not necessarily those of the Department of Veterans Affairs or the Robert Wood Johnson Foundation.

Corresponding Author: Jessica Gregg, MD, PhD; Division of General Internal Medicine \& Geriatrics, Oregon Health \& Science University, 3181 SW Sam Jackson Park Rd. L-475, Portland, OR 97201, USA (e-mail: greggj@ohsu.edu).

\section{REFERENCES}

1. Jacobs E, Chen AH, Karliner LS, Agger-Gupta N, Mutha S. The need for more research on language barriers in health care: a proposed research agenda. Milbank Q. 2006;84(1):111-33.

2. Cheng EM, Chen A, Cunningham W. Primary language and receipt of recommended health care among Hispanics in the United States. J Gen Intern Med. 2007;xx:xxx-xxx.

3. Freeman GK, Rai H, Walker JJ, Howie JG, Heaney DJ, Maxwell M. Non-English speakers consulting with the GP in their own language: A cross-sectional survey. Br J Gen Pract. 2002;52(474):36-8.

4. Lee LJ, Batal HA, Maselli JH, Kutner JS. Effect of spanish interpretation method on patient satisfaction in an urban walk-in clinic. J Gen Intern Med. 2002;17(8):641-5.
5. Perez-Stable EJ, Napoles-Springer A, Miramontes JM. The effects of ethnicity and language on medical outcomes of patients with hypertension or diabetes. Med Care. 1997;35(12):1212-9.

6. Fernandez A, Schillinger D, Grumbach $\mathbf{K}$, et al. Physician language ability and cultural competence. An exploratory study of communication with Spanish-speaking patients. J Gen Intern Med. 2004;19 (2):167-74.

7. Ngo-Metzger Q, Sorkin DH, Phillips RS, et al. Providing high quality care for limited English proficient patients: the importance of language concordance and interpreter use. J Gen Intern Med. 2007;xx:xxx-xxx.

8. Gany F, Leng $\mathbf{J}$, Shapiro E, et al. Patient satisfaction with different interpreting methods: a randomized controlled trial. J Gen Intern Med. 2007; $x x: x x x-x x x$

9. Jacobs EA, Sadowski LS, Rathouz PJ. The impact of an enhanced interpreter service intervention on hospital costs and patient satisfaction. J Gen Intern Med. 2007; xx:xxx-xxx.

10. Saussure F. Course in General Linguistics. Peru, IL: Open Court; 1986

11. Seleskovitch D. Interpretation: a psychological approach to translating. In: Brislin R, ed. Translation: Applications and Research. New York, NY Gardner Press; 1976:92-116.

12. Norris WM, Wenrich MD, Nielsen EL, et al. Communication about endof-life care between language-discordant patients and clinicians: insights from medical interpreters. J Palliat Med. 2005;8(5):1016-24.

13. Karliner LS, Perez-Stable EJ, Gildengorin G. The language divide. The importance of training in the use of interpreters for outpatient practice. $J$ Gen Intern Med. 2004;19(2):175-83.

14. Moreno MR, Otero-Sabogal R, Newman J. Testing dual-role staffinterpreter linguistic competency in an integrated healthcare system. J Gen Intern Med. 2007; xx:xxx-xxx.

15. Lie D, Boker J, Bereknyei S, et al. Validating measures of third-year medical students' use of interpreters by standardized patients and faculty observers. J Gen Intern Med. 2007;xx:xxx-xxx.

16. Gadon M, Balch GI, Jacobs EA. Caring for patients with limited English proficiency: the perspectives of small group practitioners. J Gen Intern Med. 2007;xx:xxx-xxx.

17. Gany F, Kapelusznik L, Prakash K, et al. The impact of medical interpretation method on time and errors. J Gen Intern Med. 2007;xx: $\mathrm{xxx}-\mathrm{xxx}$.

18. Kulick D. Language Shift and Cultural Reproduction: Socialization, Self and Syncretism in a Papua New Guinea Village. Cambridge: Cambridge University Press; 1992.

19. Schieffelin BB. Marking time: the dichotomizing discourse of multiple temporalities. Curr Anthropol. 2002;43(suppl):43S5-17.

20. Hymes D. Foundations in Sociolinguistics: An Ethnographic Approach. Philadelphia, PA: University of Pennsylvania Press; 1974.

21. Gumperz J. Sociolinguistics and communication in small groups. In: Pride JB, Holmes J, eds. Sociolinguistics. Harmondsworth: Penguin Books Ltd; 1972:203-24

22. Parker R. Acquired immunodeficiency syndrome in urban Brazil. Med Anthropol Q. 1987;1(2):155-75.

23. Dohan D, Levintova M. Barriers beyond words: cancer, culture and translation in a community of Russian speakers. J Gen Intern Med. 2007; $x x: x x x-x x x$.

24. Gregg J. Virtually Virgins: Sexual Strategies and Cervical Cancer in Recife, Brazil. Stanford, CA: Stanford University Press; 2003.

25. Sontag S. Illness as Metaphor. New York, NY: Vintage Books; 1978.

26. Long So, Long BD. Curable cancer and fatal ulcers. attitudes toward cancer in Japan. Soc Sci Med. 1982;16:2101-8.

27. Hasselkus BR. The family caregiver as interpreter in the geriatric medical interview. Med Anthropol Q. 1992;6(3):288-304.

28. O'Neil JD. The cultural and political context of patient dissatisfaction in cross-cultural clinical encounters: a Canadian Inuit study. Med Anthropol Q. 1989;3(4):325-44.

29. O'Neil JD, Koolage WW, Kaufert JM. Health communication problems in Canadian Inuit communities. Arctic Med Res. 1988;47(suppl 1):37478.

30. Carrillo JE, Green AR, Betancourt JR. Cross-cultural primary care: a patient-based approach. Ann Intern Med. 1999;130:829-34.

31. Saha S, Shipman SA. The Rationale for Diversity in the Health Professions: A Review of the Evidence. Washington, DC: Health Resources \& Services Administration; 2006. Available at: http://bhpr. hrsa.gov/healthworkforce/reports/diversity. Accessed August 29, 2007. 